\title{
A Study on Understanding Internet Ethics and Improving Practice by Making UCC
}

\author{
Jongwan $\mathrm{Kim}^{1}$, Hee-Jae Kim ${ }^{2}$, and Soon-Cheol Kim ${ }^{3}$ \\ ${ }^{1,3}$ Division of Computer and Information Engineering, Daegu Univ., Korea \\ ${ }^{2}$ Division of Computer and Communication Engineering, Daegu Univ., Korea \\ 1jwkim@daegu.ac.kr, ${ }^{2}$ heejae0305@daegu.ac.kr, ${ }^{3}$ kimsc@daegu.ac.kr
}

\begin{abstract}
To effectively deliver Internet ethics to students, we have utilized some videos related to Internet ethics in the class. Since the latest video presentation and its discussion were performed, it was helpful for students to recognize the internet ethical issues. However, simply passive video watching is insufficient in terms of improving student learning outcomes and practicing. In this work, two or three students teamed up to produce a UCC about internet ethics. These team project teaching methods are effective in helping students actively participate in class and understand concepts by producing videos themselves. In addition, each student can look back on his/her ethical attitude in everyday life and gain the effect of improving it. Through questionnaires of the students, we confirmed that the UCC project teaching method is effective for students' understanding of internet ethics and promotion of practice.
\end{abstract}

Keywords: Internet ethics, Understanding and practice education, UCC production, Team project education

\section{Introduction}

Ethics is human behavior that must be practiced in human societies, and what is to be observed in the relationship between people and people. In the knowledge and information society where the Internet is used as a routine, various ethical problems have been happening in industrialized societies. Internet ethics, a branch of applied ethics, copes with internet related problems for ethical inquiry by D. Langford. With the development of IT technology, internet ethics education is urgently needed because of leakage of personal information, flooding and addiction of information, increased access to harmful information, copyright infringement and information security. It is common practice to use the internet and multimedia technology for teaching lessons from the use of textbooks or fixed bulletin boards.

The emergence of new IT technologies and the Internet has allowed us to share and collect more material with the help of social networking services (SNS) such as blogs, Cyworld, Facebook, Twitter, KakaoTalk and Snapchat as well as YouTube including video and audio. According to a study done in the U.S., incorporating videos in the classroom leads to increased retention of information by students and helps them comprehend the material quicker than students who are not exposed to videos [1].

In 2001, information ethics education was implemented in elementary and middle schools to prevent information dysfunction in Korea. Now, most schools enact information communication ethics or internet ethics education. According to a study focused on schools

Article history:

Received (January 9, 2018), Review Result (February 17, 2018), Accepted (March 11, 2018) 
and the government, as well as families and society, people feel the need for teenagers to be educated in terms of Internet ethics [2]. Choi et al. applied media literacy, which can independently understand various types of media, to internet ethics education. In other words, they presented a teaching method where we teach students how to correctly use the internet, rather than completely blocking the internet from students. They wanted to promote the positive side of the internet by presenting this new and original method [3]. A study on the change of ethical consciousness after applying the learning model through discussion and writing based on problem-based learning (PBL) to Internet ethics class was conducted [4]. The study also showed that there is a statistically significant improvement in autonomy and responsibility areas. In addition, the results of the t-test showed that there was a significant effect on both the thinking and the attitudes toward the information communication ethics of the experiment group in the study on the information communication ethics teaching method through the UCC production project class [5].

The contents of the Internet ethics course for Korean college students cover various topics such as the Internet and daily life, legal problems such as copyright infringement and defamation, personal information infringement, harmful information circulation and internet dysfunction of hacking [6]. On the other hand, American universities are lecturing on professional ethics for university students and graduate students in computer-related departments that will grow as future computer experts on computer ethics [7]. In the United States, they are promoting computer ethics awareness among computer professionals and those working in the computer field. On the other hand, it is understood that the purpose of this course is to educate general students and adults about internet ethics in Korea and develop sound internet citizenship through them.

In this work, we propose a teaching method of internet ethics video production to enhance students' learning effect and willingness to practice based on their experiences of lecturing Internet ethics for university students for several years. Especially, in contrast to pre-collected video watching lessons performed by other researchers, the students construct their own teams of 2-3 persons to produce UCC (User Created Contents) related to Internet ethics. And we will analyze how they affect the students' will to practice Internet ethics.

\section{Understanding and practicing Internet ethics}

\subsection{Improvement of Internet ethics education}

We have conducted a demonstration practice classroom teaching method that explains the topic description with the pre-collected video files related to the internet ethics class. This video demonstration-practice class method has been confirmed by the lecture evaluation of students at the end of the semester that students' understanding of Internet ethics class and their satisfaction for the class are improved [8]. However, the videos produced in the past seemed to reduce student interest and lack of subjective learning effect. Therefore, we felt the necessity of research that students formed a team to make Internet ethics UCC and to study the effect of learning. Previous work [9] of the authors has conducted a project-based learning method for students to design a topic of interest, create a storyboard for the topic, and produce a UCC that describes the learning effect of the team project. At this time, we surveyed the students and analyzed the responses. As a result of the survey analysis, it was confirmed that the learning effect is increased and the understanding of the class is improved by conducting the learner participatory practice lesson that the students construct UCC directly compared with the Internet ethics class of simple video viewing method [9]. 
In the meantime, this work allowed students to verify their copyright infringement on their videos, and to write a report on the effectiveness of the term project to check their willingness to practice Internet ethics after producing the videos. As a result of these efforts, students' understanding of internet ethics has been improved as well as their willingness to practice in daily life, compared to the previous method [9]. The grading criteria shown in [Table 1] are presented in the class for students so that assignments can be made. The items in [Table 1] are the same as in the previous study [9], but the percentage of UCC production itself has been increased from $35 \%$ to $50 \%$ by changing the rating percentage. This is because some of the students in the previous lessons spent a lot of time and effort on producing the videos, but they complained about the low score of $35 \%$.

Table 1. Evaluation criteria for UCC project

\begin{tabular}{|c|c|}
\hline Evaluating items & Percentage \\
\hline Idea's novelty to choose a topic & $10 \%$ \\
\hline Scenario or story description & $15 \%$ \\
\hline UCC production level & $50 \%$ \\
\hline $\begin{array}{c}\text { Logical explanation on learning effects and its } \\
\text { willingness to practice }\end{array}$ & $25 \%$ \\
\hline Total & $100 \%$ \\
\hline
\end{tabular}

In particular, several students use the vast number of videos on the Internet to create UCCs. For example, some UCC projects show some of the Internet-gathered videos, describe the problems of the themes, and develop ways to improve them. In past lessons, this production was allowed, but there were cases where the distinction between whether it was produced by the students and whether most of the videos of the other persons were utilized was ambiguous. Although it is good for the instructor to find such a difference, there are limits to the difficulty of identifying numerous Internet ethics-related videos. In this work, students were asked to state in their report that their work was not in violation of copyright, and if they violated this guideline, they were notified that they would score 0 points. As a result of this announcement, a small number of teams in past classes didn't give the presentation and received 0 points for the UCC production item. However, there were no teams in this course. Also, before the end of the semester, each UCC team briefly explained the subject of its work to all students, and all the students watched it together. This has enabled the students to make themselves free from copyright infringement and improved cross-copyright searches. Through these team project presentations and discussions, students also had a meaningful time to share experiences on project topic selection and production experience.

\subsection{Internet ethics class survey and analysis}

The purpose of this research is to analyze the internet ethics UCCs and team project reports on its practice will be submitted by 126 students who took courses in the first semester and second semester of 2017. First, 70 students in the first semester produced 28 UCCs and 4 teams received 100 points. In the second semester, 56 students performed 22 projects and 5 works were awarded. In the topic selection, the topics of internet addiction including SNS were the most, and there were many topics related to copyright infringement, malicious comment damage, and cyber-crime. This is presumed to be due to students' perception that they are the most frequently encountered issues on the Internet, and that they should prevent damages related to money and unethical behavior experiences that they do not know according to the internet ethics knowledge ignorance. 
We will perform statistical analysis on the question items of [Table 2] for 98 students who submitted the survey among the 126 students who took the first semester and the second semester of 2017. In the First semester of 2017, 49 students answered the questionnaire, and another 49 respondents answered the questionnaire in the second semester. The results of the SPSS statistical analysis were as follows: First, Cronbach's alpha reliability analysis of the questionnaire responses was 0.837 (First semester 2017), 0.812 (Second semester 2017), 0.826 (2017 whole year). The reliability of the questionnaire is reliable because the alpha value of Cronbach is more than 0.8 .

Table 2. Internet ethics questionnaire items for students

\begin{tabular}{|c|}
\hline Question items \\
\hline 1. Do you think Internet ethics is an easy subject? \\
\hline 2. What was the level of understanding of Internet ethics before class? \\
\hline 3. What was the degree of understanding of Internet ethics after class? \\
\hline 4. Was the use of textbooks and handouts appropriate? \\
\hline $\begin{array}{l}\text { 5. Has the use of ethics videos (including UCCs from previous students) led students } \\
\text { to pay attention to the class? }\end{array}$ \\
\hline 6. Did viewing the ethics video help you understand the Internet ethics concept? \\
\hline $\begin{array}{l}\text { 7. Does the experience of UCC production according to the UCC team project help } \\
\text { to understand and practice the Internet ethics concept? }\end{array}$ \\
\hline 8. Do you think the lecture is effective overall? \\
\hline 9. Will this lesson help you practice your future Internet ethics? \\
\hline
\end{tabular}

The correlation analysis of the questionnaire items in [Table 2] was performed for 98 respondents. As a result of analyzing the correlations between the items, the correlation coefficient between the 7th and 6th items of the First semester, the second semester and the 2017 whole year were $0.755,0.734$ and 0.741 , respectively. It can be understood that the experience of making UCC by performing the UCC team project together with watching the video of ethics helps the understanding and practice of internet ethics concept. In addition, the correlation coefficients of items 9 and 8 of $0.826,0.685$, and 0.768 indicate that students who think that lectures are generally effective will help practice future Internet ethics. Next, we can see that the use of the video of ethics that draws attention to the class will help to practice their future internet ethics from the correlation coefficients $0.769,0.579,0.682$ of the 9th and 5th questions. Finally, it was confirmed that the overall lecture was effective with the use of proper textbooks and handouts through the correlation coefficients of $0.673,0.605$, and 0.646 for items 8 and 4.

Table 3. Correlation according to Internet ethics questionnaire items by semester in 2017

\begin{tabular}{|c|c|c|c|c|c|c|c|c|c|c|}
\hline Semesters & Items & Item1 & Item2 & Item3 & Item4 & Item5 & Item6 & Item7 & Item8 & Item9 \\
\hline & Item1 & 1.000 & .030 & -.075 & -.154 & -.065 & -.125 & -.202 & .049 & -.061 \\
\cline { 2 - 11 } & Item2 & & 1.000 & .363 & .533 & .577 & .147 & .290 & .596 & .458 \\
\cline { 2 - 11 } $\begin{array}{c}2017 \\
\text { First } \\
\text { Semester }\end{array}$ & Item3 & & & 1.000 & .497 & .210 & .117 & .349 & -.008 & -.007 \\
\cline { 2 - 11 } & Item4 & & & & 1.000 & .626 & .388 & .579 & .673 & .639 \\
\cline { 2 - 11 } & Item5 & & & & & 1.000 & .566 & .586 & .707 & .769 \\
\hline
\end{tabular}




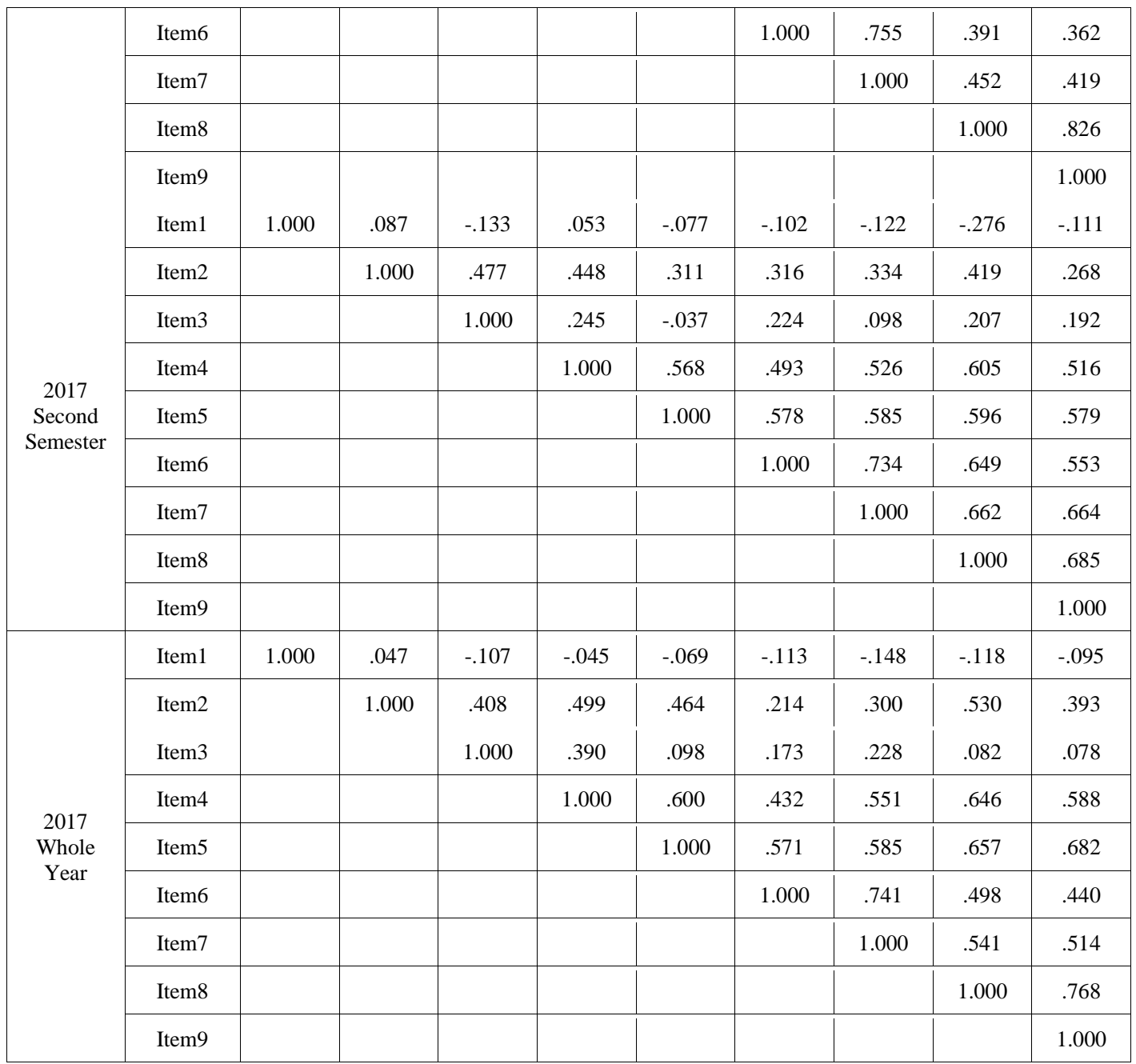

\section{Conclusion}

In this research, students autonomously formed a team to produce a UCC on Internet ethics and to write a report describing the learning effect. The purpose of this work is to confirm that the concept of Internet ethics is understood and the practice consciousness is cultivated. As a result of analyzing the questionnaires collected by the students, it was confirmed that the proposed method contributes to students' understanding of Internet ethics and improvement of their willingness to practice. In particular, at the end of the semester, a video demonstration was held to provide students with the opportunity to explain their work to the other students, and to watch the presentation of the other teams. In addition, copyright infringement verification was conducted to reduce the burden on the instructor and contribute to fair credit evaluation. In the future, we will analyze the questionnaires collected from the students in more detail, and find improvements in the classroom. We also need to take a closer look at what students consider when choosing a topic. And it is necessary to supplement the research that verifies whether students practice after the UCC project.

\section{References}

[1] B. Courts and J. Tucker, "Using technology to create a dynamic classroom experience," Journal of College Teaching \& Learning, vol.9, no.2, pp.121-127, (2012) DOI: 10.19030/tlc.v9i2.6907 
[2] J. Son and Y. Bae, "Direction of education for Internet ethical education," Proc. of Fall Conference, Korea Multimedia Society, pp.509-510, (2010)

[3] J. Choi, M. Lee, and Y. Son, "Media literacy as an internet ethics education methodology," Proc. of Spring Conference, Korea Information Processing Society, pp.1563-1566, (2011)

[4] J. Park and O. Kang, "An internet ethics learning model based on PBL," Journal of Korean Association of Computer Education, vol.15, no.2, pp.29-36, (2011)

[5] S. Han, "Research for the information and communication ethics education model through the project instruction using UCC (User Created Contents)," M.S. thesis, Korea National University of Education, (2009)

[6] Korean ethics council on internet, Internet Ethics, Ehan Media, Gyeonggi-do, Korea, (2012)

[7] S. Baase, "A gift of fire: Social, legal, and ethical issues for computing technology," 4th ed., Prentice Hall, (2013)

[8] J. Kim and H. Kim, "Case study of internet ethics lecture using videos and demonstration practice," Journal of Korean Association of Computer Education, vol.16, no.3, pp.23-30, (2013)

[9] J. Kim and H. Kim, "Improving internet ethics understanding by making related UCCs," Journal of the Korea Industrial Information Systems Research, vol.20 no.3, pp.1-9, (2015) DOI: 10.9723/jksiis.2015.20.3.001 